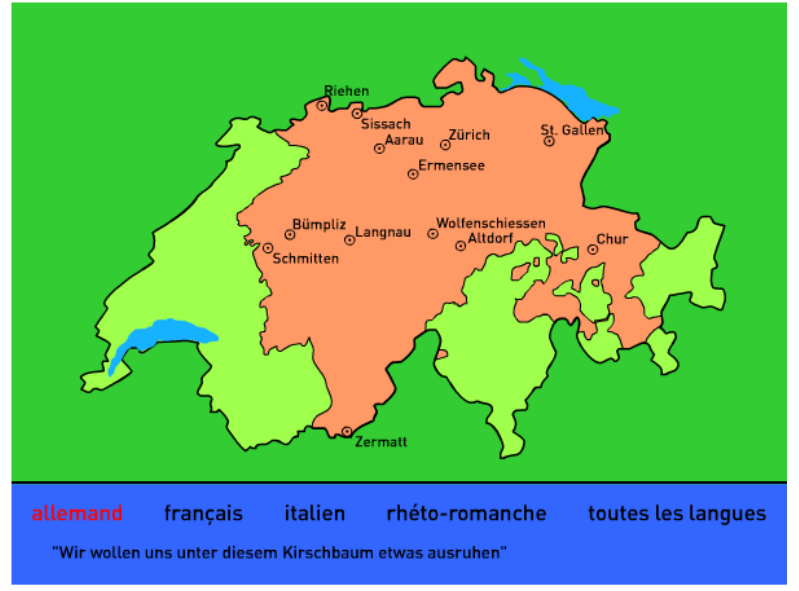

\title{
A geografia, a identidade das línguas e as divisões de langues e dialectes no site de relações estrangeiras da suíça: reflexões sobre o sentido da designação no texto
}

The geography, languages identity and enunciative operations on langues and dialects on the website of the Switzerland's Federal Department of Foreign Affairs: reflections about the sense of designation on the text

André Stefferson M. Stahlhauer ${ }^{1}$ Soeli Maria Schreiber da Silva ${ }^{2}$

\begin{abstract}
Resumo:
Propomos, neste artigo, uma leitura/ interpretação do funcionamento da designação de língua em uma versão do site do Département fédéral des affaires étrangères DFA da Suíça (Departamento Federal de Relações Estrangeiras), www.swissworld.org/fr, a fim de mostrar que sua enunciação e sua inscrição na internet se dão quando a língua é recortada pelas relações que particularizam os lugares de dizer na era da informação. Nesse sentido, pretendemos observar como a Suíça, como Estado, representa suas línguas e suas diferenças em um site pelas operações enunciativas que o locutor-WebEstado inscreve no funcionamento da designação de Langues et dialectes (línguas e dialetos), no texto do site.
\end{abstract}

Palavras-chave: línguas, designação, texto

\begin{abstract}
:
The purpose of this article is to offer a reading / interpretation of the functioning of language designation on a version of the website of the Département fédéral des affaires étrangères (DFA), in Switzerland (Federal Department of Foreign Affairs), www.swissworld.org/fr, in order to show that both its enunciation and its inscription on the internet have been affected by the relations that particularize the social position in contemporary times and in the information age. We intend to observe how Switzerland, as a state, represents its languages and its differences on a website by enunciative operations that the locutorWebEstado inscribes in the functioning of the designation of Langues et dialectes (languages and dialects), in the website's text.
\end{abstract}

Keywords : languages, designation, text

\footnotetext{
${ }^{1}$ Professor da área de Linguística no Departamento de Letras da UFSCar. Pesquisador e colaborador da Unidade de Pesquisa em Estudos Históricos, Políticos, e Sociais da Linguagem-UEHPOSOL/UFSCar. Email: andrestefferson@yahoo.com.br. Rod. Washington Luís km 235 - SP-310 - São Carlos CEP 13565905

${ }^{2}$ Professora do Departamento de Letras e coordenadora da Unidade de Pesquisa em Estudos Históricos, Políticos e Sociais da Linguagem-UEHPOSOL/UFSCar. E-mail: xoila@terra.com.br. Rod. Washington Luís km 235 - SP-310 - São Carlos CEP 13565-905
} 
Em um tempo em que as línguas têm um papel decisivo na constituição das identidades, dos sujeitos, dos seus falantes, de seus locutores, elas são objeto de inúmeras formas de enunciação: podem ser objetos de Estados, de instituições, empresas, editoras, etc. Em linhas gerais, este trabalho pretende mostrar uma interpretação do funcionamento da designação de língua em uma versão do site do Département fédéral des affaires étrangères DFA (Departamento Federal de Relações Estrangeiras $^{3}$ ), www.swissworld.org/fr, uma vez que, sua enunciação (e sua inscrição na internet) se dá recortada pelas relações que particularizam os modos de enunciar na era da informação. Nesse sentido, pretendemos observar como a Suíça, como instituição, como Estado, representa suas línguas em um site da internet.

Do ponto de vista dos estudos enunciativos, tal como em Eduardo Guimarães (2002), o sentido da designação é construído no acontecimento da enunciação. Fazemos, então, uma análise de alguns processos envolvidos no modo de enunciar e representar as línguas e seus falantes na internet a fim de mostrar o funcionamento político da representação. Sendo assim, investigamos a construção do sentido da designação de Allemand, alemão; français, francês; italian, italiano e romanche, romance, para mostrar as disparidades no modo de representar e o modo de integrar o texto Langues et Dialectes, no site oficial da Suíça ${ }^{4}$, nas operações enunciativas que inscrevem os sentidos das línguas. Para tanto, levamos em conta os meios pelos quais as Políticas Linguísticas ressignificam as línguas da Suíça em seu modo de "repartir" em cantões, por noções etno-geográficas, como, por exemplo, fala-se alemão na Suíça-alemã ou francês na romandie, a Suíça românica, em sua configuração empírica: os dialetos, os $\operatorname{acentos}^{5}$ e as línguas.

Pretendemos, com isso, ainda, avançar no desenvolvimento de métodos e procedimentos de análise das relações entre línguas que vimos realizando em Stahlhauer (2010) e (2014). Retomamos a discussão que fizemos no trabalho de tese de Stahlhauer $(2014)^{6}$, na qual realizamos, entre outras reflexões, análises sobre o funcionamento

\footnotetext{
3 Tradução nossa.

${ }^{4}$ Os recortes foram realizados de 2010 a 2014. Hoje o site do Departamento Federal de relações estrangeiras apresenta outra configuração. Não é mais permitido seu acesso na versão antiga. Quando clicamos no link, somos redirecionados diretamente para o endereço https://www.eda.admin.ch, em sua versão em alemão.

5 Traduzimos, neste momento accent, do francês, como acento. Posteriormente vamos considerar o termo como sotaque, tal como seria o seu equivalente em português.

6 STAHLHAUER, André S. M. A representação de línguas no ciberespaço: um funcionamento enunciativo na contemporaneidade. Tese de Doutorado. Outubro/2014. UFSCar- São CarlosSP.Outubro/2014.Impresso. Pesquisa realizada com bolsa FAPESP no Brasil (2010/15546-0) e na Suíça
} 
enunciativo da designação de língua em sites oficiais de alguns países, como Brasil, França e Suíça.

A questão que se coloca em torno da designação é o seu funcionamento no acontecimento da enunciação, de acordo com Eduardo Guimarães (2002), bem como o modo como ela significa no texto, tomando como base seus estudos em Análise de texto, em Guimarães (2011). Sendo assim, uma das projeções que fazemos sobre a enunciação da designação no site é a de que, uma vez inscrita em um mapa, sua significação se dá por modos de escrita da internet, os links, que, neste caso, são enunciações que redividem o geográfico em reescriturações de acento, dialeto e sotaque nos nomes das regiões e das cidades em que elas são faladas.

\section{Os limites, as fronteiras, as línguas.}

Em seu quadro oficial e nacional, na Suíça, se falam as quatro línguas: o alemão, o francês, o italiano, mais o romance, língua nacional e oficial no cantão dos Grisões. As três primeiras são também, a língua da Alemanha, da França e da Itália. Fronteiras muito bem definidas por aduanas. Organizações políticas distintas. O movimento de um lado ao outro já foi diferente, mais conflituoso. Hoje em dia os trens, os ônibus, os tramways ou barcos ligam um lado e o outro das fronteiras. Os Cantões (Suíça), os Departamentos (França), Províncias (Itália) e os estados (na Alemanha) se delimitam e se interligam por fronteiras terrestres, montanhas, lagos ou rios. Os cantões de Genebra e Vaud (Lausanne) se limitam e se ligam aos departamentos franceses da Haute-Savoie (Alta-Saboia), cuja capital é Annecy-Fr, e a Savoie (Saboia) - Chambéry - Fr, pelo Lac Léman (lago Léman) ou Genfersee (Lago de Genebra), em alemão. Além do francês, língua oficial e nacional, fala-se ali o que é hoje o Franco-Provençal ou Artpitan (Artpitano), língua de cultura dessa região. É importante ressaltar que esses modos de designar a relação com a organização da unidade de um Estado e de suas partes, como departamento, ou como um cantão, ou como uma província etc., determinam um modo de distribuição das línguas. De uma política centralizadora na França, se tem o Francês, das províncias da Itália se tem o italiano redefinindo seus dialetos, e da política 
federalista da Suíça, dos cantões, tem-se línguas diferentes que se redividem em dialetos, no caso do alemão, e nos sotaques (accent), no caso do Francês e do Italiano ${ }^{7}$.

Em função de suas coordenadas sócio-históricas, a Suíça manteve-se fiel à relação povo/língua, ou seja, os povos dos estados antes independentes garantiram o direito à língua e à cultura locais, mesmo quando estes aderiram à Confederação, cuja língua oficial era o alemão. E diferentemente de outros países como França e Alemanha, o seu sistema político não suportava a noção de Estado-Nação, como afirma François Grin (1999), pois a questão da língua não pôde ser colocada como elemento unificador. O papel do mito Helvético se debruçou sobre outros aspectos para caracterizar o imaginário de povo: a higiene, a qualidade de serviços, a tradição humanitária. Isso foi o que garantiu a cada cantão o direito de escolher sua(s) língua(s) oficial(ais), o que permitiu a sua "repartição" de línguas em cantões, segundo as origens das "nações" que ali viviam. A língua não teve papel decisivo, embora fosse central, para a elaboração da unidade política, diferentemente da França, país organizado em Estado centralizado, que via na unidade da língua, do povo, a solução para a constituição de um Estado uniforme, pela divisão de seus bens comuns: um povo, uma língua, uma nação, um Estado.

No entanto, todo um outro trabalho de justificativa deveria ser feito na Europa não somente reacionária, mas onde triunfava também uma estruturação rígida do espaço. Ela estava embasada sobre uma hipótese de uma seguinte correspondência necessária entre o Estado e a Nação, entre a Nação e o Povo, e entre o Povo e a Língua. A tradição francesa era um exemplo mais profícuo disso. A questão da diversidade das línguas não podia ficar em silêncio, nem mesmo ser tratada de passagem como um elemento periférico da identidade suíça. Era necessário ao contrário, que ela fosse central, e por isso recolocar em causa, essas sucessivas correspondências. (GRIN 1999, p. 253, Tradução nossa)

A Suíça historicamente se configura pela heterogeneidade dos povos distribuídos em vinte e seis cantões. Esses povos trouxeram consigo as línguas que falavam. A Confederação Helvética tem a mesma composição nacional desde 1848 (GRÉGOIRE NAPPEY \& MIX \& REMIX, 2013), data da criação do Estado federal, onde foi elaborada a primeira constituição federal, que institui um Estado federalista. Dezenove cantões germanófonos, quatro cantões francófonos, três bilíngues (Francês e alemão), Valais, Friburgo e Berna; um cantão trilíngue: fala-se italiano, alemão e romance nos Grisões. Essas regiões linguísticas mais o último cantão deram origem aos três outros grupamentos linguísticos que compõem a atual Confederação de Estados: Suíça

\footnotetext{
${ }^{7}$ Salienta-se que estamos interpretando acento por dialeto, na tradução do francês, do italiano e do francês ao português. Ou seja, reinterpretamos essa divisão da enunciação dessas conceituações de um ponto de um modo específico.
} 
românica, Suíça alemã e a Suíça italiana. Essas são as três macrorregiões que se caracterizam por suas diferentes configurações nacionais. Cada cantão com seu "mono" ou "bilinguismo". Só os documentos federais são escritos nas quatro línguas, mas, sobretudo, em alemão. O caso do reconhecimento do romance é outra inovação. O acordo se dá entre a confederação e algumas comunas dos Grisões, onde se fala o retoromance.

A Suíça é um país que se destacou, no meio da Europa, por sua maneira diferente de organizar a sua política. Como já dito anteriormente, a língua não teve um papel decisivo, uma atribuição "política" de dominação ou como medida de partilha de bens comuns. Segundo Grin (2000, p. 258-259) há três instrumentos principais da gestão das línguas: 1) a territorialidade, 2) a liberdade da língua, 3) a subsidiaridade, que serviram de modelo para toda medida sobre a língua. Este modelo se "verse et renverse" sobre o unilinguíssimo ou sobre o monolinguíssimo (GRIN 1999, p. 259260), segundo suas categorias de análise. Ou seja, o pluri, multilinguismo na Suíça é regulado por uma prática monolíngue, pois é opcional ao cantão o ensino de alemão, a língua majoritária. F. Grin observa as políticas linguísticas na Suíça questionando a sua validade e autenticidade para a continuação de uma "repartição" democrática e inclusiva frente ao inglês, sempre incluído nas escolas e universidades e em relação às línguas de imigração como o português e o albanês.

Todavia, neste ponto, é necessário distinguir nossa posição da de Grin (1999), pois em seu trabalho sobre "Gestion des langues à la Suisse" ele requisita a inclusão dessas línguas em instâncias institucionais. A nossa questão não é diretamente essa. Pretendemos aqui mostrar que, para além das práticas de inclusão, a questão das línguas e de suas diferenças passa por sua representação e por suas redivisões em espaços de enunciação (cf. GUIMARÃES 2002) e que, sobretudo, passa pelo modo como isso significa em um texto, que reescreve a história, ressignifica os processos de distribuição das línguas aos falantes. O que nos interessa é como se dá a representação das línguas da Suíça em um site da internet e como a enunciação dessa representação ressignifica as diferentes denominações em função de sua geografia. Nesse sentido, o nosso olhar recai sobre a inscrição desses processos na história, na escrita de um mapa de repartição de Línguas e dialetos.

Passemos, então, a exemplificar os procedimentos de análise.

2. Os modos de enunciar na internet em um site: suas instâncias, seus caminhos. 
Em Semântica do Acontecimento, Guimarães (2002) mostra um funcionamento da temporalidade que organiza a enunciação em uma revista: seu índice. Para ele, o modo de enunciar em um índice projeta uma futuridade no modo de organizar a leitura da revista, em que o depois, o porvir, instaura o tempo de locução e não uma simples ordem de leitura. É o tempo do Locutor que fala em uma revista de um modo específico, o que é diferente do tempo do "escritor" do texto, tempo em que o texto é escrito para ser publicado.

O caráter de indexação, configurado pela "objetividade", "transparência", "neutralidade" (e adicionamos o excesso), são características da era da informação, da informatização e seus modos de "tratamento textual". Ou seja, o modo de organizar estes materiais implica em procedimentos que significam os processos e os espaços: as placas em espaços públicos, os manuais sobre povos, regiões, territórios, e os sites, cada qual com seu modo de textualizar.

Vale ressaltar que a internet, em seu modo de organizar a "informação" através dos links, permite o "manejo" de diferentes tipos de materiais (orais, escritos, vídeos, mídias em geral etc.), o que inscreve outras relações de leitura alocutadas no texto. A internet, assim, simula outros tipos de leitores, diferentemente de um livro, revista em papel, nos quais a "finitude" do material não permite tal leitura do mesmo modo. ${ }^{8}$

Quando acessamos um site, encontramos algo que lhe é próprio e específico, diferente da leitura em outros tipos de suporte, como o papel. Ou seja, transita-se de um "lugar" a outro e assim os dígitos são traduzidos em palavras pelas máquinas. O esquema de organização das informações em árvores apaga inúmeros processos relativos ao funcionamento do sentido, principalmente no que tange ao sujeito e à língua, pois a "prática" e a "objetividade" são as características do paradigma informacional em oposição às reflexões, teorizações. Por meio de dígitos traduzidos em palavras, "chegamos" aos endereços dos sites.

O texto da "era digital" carrega essas características. Os links significam esse caráter de índice, de indexação, tal como a informática designa o termo, e "liga" o sentido entre o que é designado/referido no nome/título e a outra parte do texto. Esse é o

\footnotetext{
${ }^{8}$ Isso configura ainda, outro modo de "gerir" e regular a memória do que se disponibiliza e lê ali. Por exemplo, para se modificar um conteúdo publicado em papel, é necessária uma reedição, um comentário, uma nota. $\mathrm{Na}$ internet, esse tipo de prática ainda é negligenciada pela sua rapidez. O conteúdo do site que analisamos mudou e não disponibiliza mais os dados da versão antiga. Isso coloca outra questão sobre os procedimentos da internet, sua movimentação, manipulação, regulação etc., que não focaremos aqui.
} 
modo como o locutorWeb ${ }^{9}$, opera sobre os enunciados na organização dos sites, suas páginas, seus textos e seus sentidos. Deste modo, a enunciação de um link caracteriza o modo específico de inscrição de enunciados, dispondo os sentidos que significam a partir de operações enunciativas dos locutores de modo a organizar esses enunciados em um texto.

No caso do site que analisamos, por ser tratar de um site oficial, do âmbito das relações institucionais da Suíça, temos um locutor-WebEstado, pois os sites são geridos pelo Estado e, nesse sentido, o Locutor é predicado por este lugar social pela oficialidade e institucionalidade que caracterizam esse tipo de enunciação. Desse modo, dois lugares sociais coexistem aí: o do locutorWeb e o do locutorEstado, que representaremos como locutor-WebEstado.

\subsection{O caminho no endereço e a língua no site}

A esfera do ciberespaço aparece constituída em seu próprio modo de enunciação inicial, o endereço do site, <www.swissworld.org/fr >, depois logo na nomeação do site e de seu slogan "Your Gateway to Switzerland", que referem o país na internet, pela designação do nome mais o /fr ou /de. Nesse caso da Suíça, há outra relação interessante, pois se seu endereço é escrito/digitado, somente com ".org" e o site abre na versão em língua inglesa diretamente, o que interpretamos como uma relação direta com a in(ex)clusão que a língua inglesa significa, enquanto língua franca, de comunicação entre falantes de nações diferentes, Guimarães (2006, p. 14). Desse modo, no site, de início, há a inscrição do locutorWeb falante de língua inglesa ${ }^{10}$.

Ainda relativamente aos modos de acesso pelas línguas, se digitarmos o mesmo, para um teste por meio do domínio ${ }^{\mathbf{1 1}}$.org/fr, ele aparece em francês, e a sigla se refere à língua francesa ou francês, pela abreviação FR e não pela abreviação do nome do país, tal como no site da França, o fr, que estabelecem uma relação de homonímia. Do mesmo modo, se testarmos o acesso através de .org/de/, o site abre em alemão, mas nesse caso, o nome da língua, do idioma, Deutsch ${ }^{12}$, em alemão, não coincide com a

\footnotetext{
${ }^{9}$ Conforme a noção de Locutor e lugar social de dizer (que figura a noção de locutor) em Guimarães (2002), pois o Locutor sempre fala em uma língua e é predicado de um modo específico, ele se configura por este modo específico de textualizar: a linkagem e seus procedimentos na internet.

${ }^{10}$ Conforme a definição que Eduardo Guimarães (2002) dá ao falante, enquanto uma categoria de uma língua.

${ }^{11}$ Tal como sugere o termo que dá acesso, o .x ou .y é uma identidade digital.

${ }^{12}$.de também designa a sigla de abreviação do país, da Alemanha, homonímia do nome da língua e do idioma, Deutsch.
} 
sigla do país, da Suíça, que é $\mathrm{CH}$, abreviação de Confederação Helvética, ou seja, é a língua que define, identifica, o modo de ler e não a referência ao país (como é o caso site da França e do site Brasil). Vale ressaltar que não há acesso pela sigla so país, por meio de $\operatorname{org} . c h$ ou $\mathrm{org} / \mathrm{ch}$, mas a sigla que abrevia o nome oficial da Suíça.

\title{
2.2 Modos de leitura e operações enunciativas.
}

Tendo em vista nossa posição teórica e metodológica, na qual se formula a questão do texto e da designação como unidade de análise, consideramos os procedimentos enunciativos que configuram as relações semânticas entre os integrantes de um texto: a sinonímia, a antonímia, a hiperonímia, a homonímia, a ambiguidade e a polissemia, pelas quais o sentido se dá operado por dois procedimentos reescrituração e articulação.

\begin{abstract}
A reescrituração é o procedimento pelo qual a enunciação de um texto rediz insistentemente o que já foi dito fazendo interpretar uma forma como diferente de si. Este procedimento atribui (predica) algo reescriturado. Esta reescrituração é o procedimento que coloca em funcionamento uma operação enunciativa fundamental na constituição do sentido de um texto. (GUIMARÃES, 2007, p 84)
\end{abstract}

E pode se dar de seis outros modos: repetição, substituição, elipse, expansão, condensação e definição e por seis modos, sinonímia, especificação, desenvolvimento, generalização, totalização e enumeração.

O outro procedimento enunciativo que estabelece relações de sentido entre palavras e expressões é a articulação. Articular é estabelecer uma relação de sentido entre unidades linguísticas em sua contiguidade.

Em virtude do modo como os elementos linguísticos, pelo agenciamento enunciativo, significam sua contiguidade. Ou seja, a organização das contiguidades linguísticas se dá como uma relação local entre elementos linguísticos, mas também e fundamentalmente por uma relação do Locutor (enquanto falante de um espaço de enunciação) com aquilo que fala. Uma articulação é uma relação de contiguidade significada pela enunciação. (GUIMARÃES, 2009, p. 51)

Conforme Guimarães (2009), a articulação se dá de três modos, por dependência, incidência e coordenação. É em uma coordenação que temos uma enumeração, por exemplo, e para se ter uma enumeração é necessário que entre os itens enumerados haja acumulação, coordenação e contato. 
Nesses sites, os enunciados (os links) se articulam e se reescrevem de modo que relacionam o que está antes, durante e depois do clique. O site, nesse sentido, é organizado por um conjunto de textos, cujos enunciados se integram operados enunciativamente por esses procedimentos.

\subsection{O sentido da designação de Langues et dialectes no site}

A página do site da Suíça $^{13}$ dá acesso ao conteúdo representado em uma animação. Analisamos os sentidos da designação de Língua e Dialeto que determinam os sentidos da expressão Dialeto nesta página:

Para acessar o registro do dialeto, é necessário escolher a "língua", depois clicar na palavra-link com o nome da cidade onde é falado o dialeto, aí é dada uma instrução ${ }^{14}$ que dá acesso aos dialetos ali representados, então se clica na palavra-link da cidade onde se fala a variante ou "acento"/sotaque ${ }^{15}$.Temos os enunciados que representam as Línguas: Alemão, francês, Italiano e reto-romance, como mostra a figura da página do site em francês, nos exemplos abaixo nas figuras dos mapas com e sem seleção de língua.

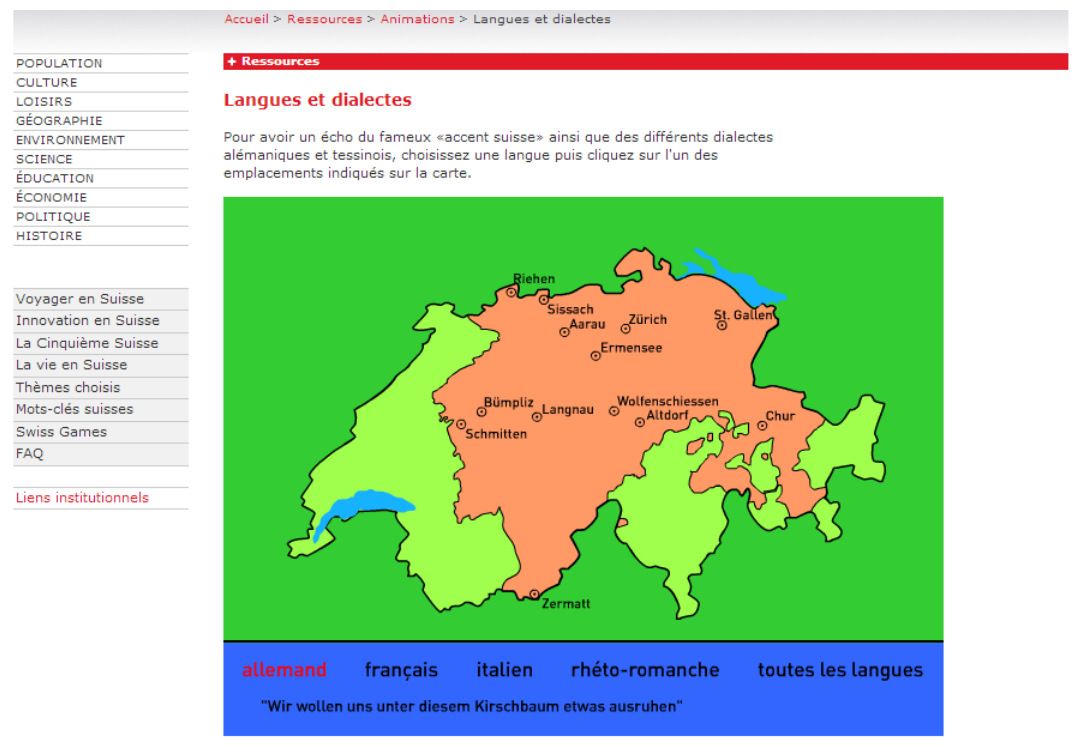

Figura 1 - Línguas e dialetos. Alemão suíço

\footnotetext{
${ }^{13}$ www.swissworld.org/fr/switzerland/ressources/animations/langues et dialectes

14 Guimarães (2002) se utiliza de uma definição de Ducrot (1984) para ilustrar como um locutor dá instruções de sentidos aos seus leitores, Ducrot (1984) apud Guimarães (2002, p. 14).

${ }^{15}$ Como sugere o termo em português.
} 


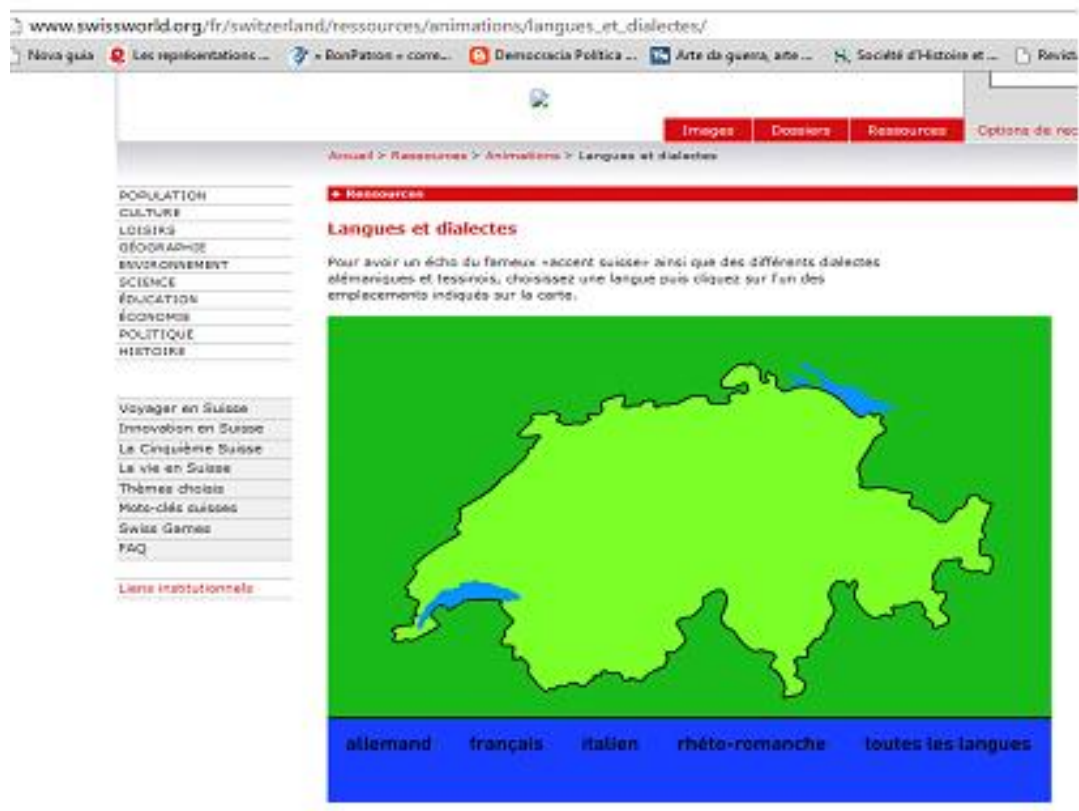

Figura 2 - Línguas e dialetos. Mapa sem seleção

Para esse recorte, podemos interpretar o texto, ao menos, de dois modos: em (A) por sua tradução em diferentes línguas alemão, francês e italiano e (B) pelo estudo da designação dessas línguas na página do site,

Iniciamos pela leitura (A) analítica relativa à instrução, nos modos de ler e os tipos de leitores, significados pela identidade das diferentes línguas, o que configura diferentes sentidos e diferentes modos de enunciar, mostramos o exemplo em três línguas, alemão, italiano e francês. Ressalta-se que em cada tradução, a introdução se apresenta em uma língua diferente, com diferentes dizeres.

\section{Sprachen und Dialekte}

(I) Für eine Hörprobe der Schweizer Dialekte klicken Sie auf die gewünschte Sprache und einen Ort. Auch wenn es zunächst nicht so tönt: alle Sprecherinnen und Sprecher sagen den gleichen Satz.

(I') Para uma amostra de áudio dos dialetos suíços clique na Língua e local desejado. Mesmo que inicialmente não soe assim: todos os falantes "dizem" do mesmo modo ${ }^{16}$.

Langues et dialectes

(II) Pour avoir un écho du fameux «accent suisse» ainsi que des différents dialectes alémaniques et tessinois, choisissez une langue puis cliquez sur l'un des emplacements indiqués sur la carte.

\footnotetext{
16 Tradução nossa.
} 
(II') Para ter um eco do famoso "acento suíço"17 e os vários dialetos "alemânicos" e tecinêses, escolha uma língua e, então, clique em um dos locais indicados no mapa.

Lingue e dialetti

(III) Per un assaggio delle pronunce e dei dialetti svizzeri nelle varie lingue svizzere, scegliere una lingua e cliccare su una località. Anche se non immediatamente evidente, la frase pronunciata è sempre la stessa.

(III') Para ter um "gostinho" das pronúncias e dialetos nas várias línguas suíças, escolha uma língua, clique em um local. Embora não seja imediatamente evidente, a frase pronunciada é sempre a mesma.

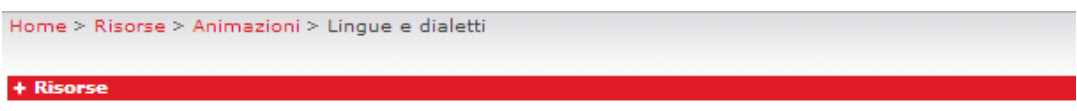

Lingue e dialetti

Per un assaggio delle pronunce e dei dialetti svizzeri nelle varie lingue svizzere, scegliere una lingua e cliccare su una località. Anche se non immediatamente evidente, la frase pronunciata è sempre la stessa:

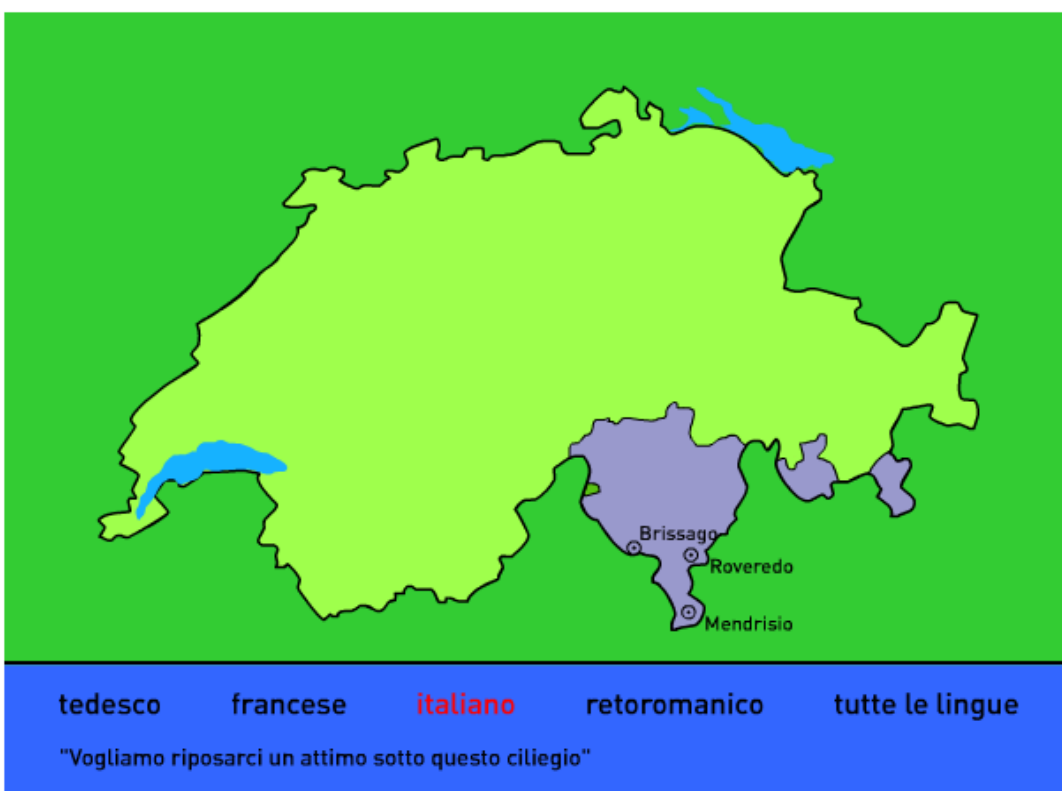

Figura 3 - Línguas e dialetos do italiano, na Suíça. Adaptada do site oficial da Suíça

Em (A) no recorte abaixo, a análise tem a ver com o modo como a interpretação dos conceitos de Língua, Dialeto e sotaque $^{18}$ (em português) são

\footnotetext{
17 Traduzimos/interpretamos accent por sotaque para melhor ilustrar a diferença entre o sentido de acento e dialeto em português, levando em conta a especificidade do uso do termo em língua portuguesa.

${ }^{18}$ Salienta-se que estamos interpretando acento por sotaque, na tradução do francês ao português.
} 
representados pelo locutor-WebEstado, que projetam seus alocutários falantes de Alemão e Italiano e francês de diferentes maneiras.

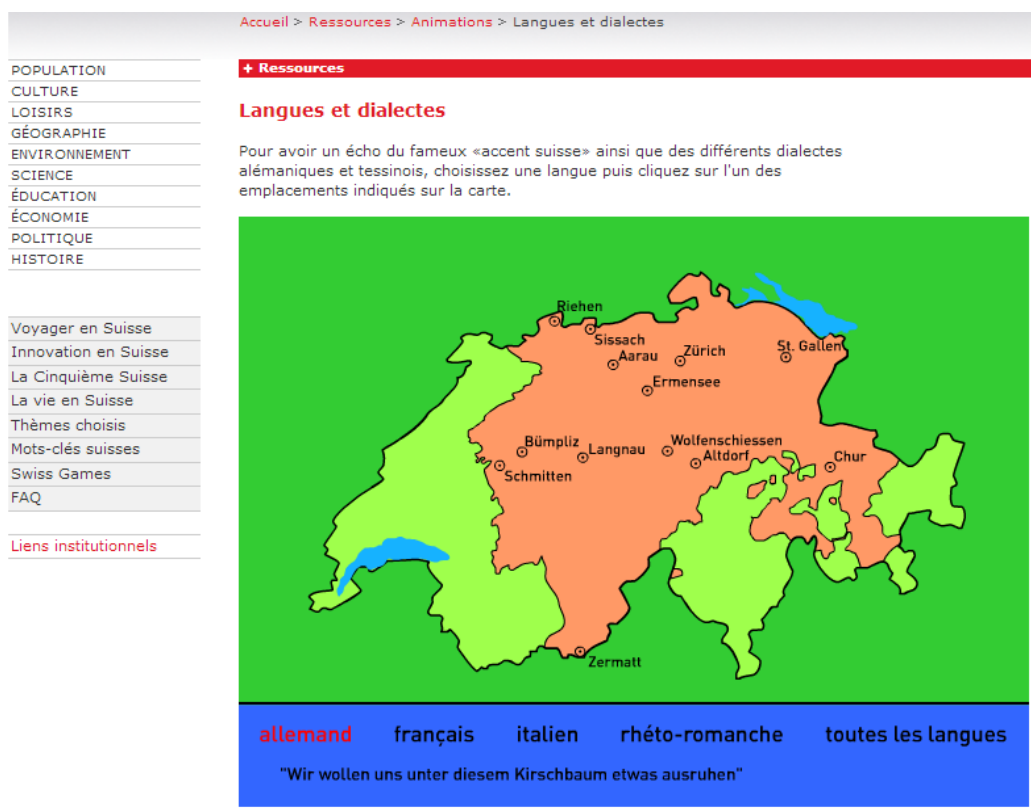

Figura 4 - Línguas e Dialetos suíços do alemão, em alemão.

Em (I), (D) Sprachen und (d) Dialekte (línguas e dialetos), significam em uma operação de substituição e especificação, em (d) Dialekte e (d') Schweizer Dialekte, como se pode ver na Figura 4.

Em (II) ${ }^{19}$, no caso do francês há uma substituição por especificação entre dialeto (dialecte) e sotaque (accent), tal como em: Langues et dialectes e «accent suisse», o que configura um modo diferente de se relacionar com a língua e sua "variação". Esse enunciado é recortado pelo memorável de que na Suíça não se fala um dialeto do francês, mas um sotaque.

Essa pequena reflexão tem a ver com o modo de representar o saber sobre a língua na relação entre Sprachen und Dialekte em (x) e (x’) e depois em Langues et dialectes e accents suisse, a fim de mostrar que a designação da palavra, não tomada como conceito ou como um objeto do mundo aqui, se dá em sua designação na enunciação, na relação entre a língua e o falante (representado nas enunciações em alemão e em francês).

Em (B) temos outro tipo de recorte, que é o modo como a textualidade é organizada pela relação de sentidos entre "langues et dialectes".

Interpretaremos os enunciados em língua francesa.

19 Damos maior enfoque a essa descrição, pois é a partir dela que interpretaremos os sentidos das designações. 
Note como o sentido de Langues e dialectes está redividido no texto:

\section{«Langues et dialectes}

Pour avoir un écho du fameux «accent suisse ${ }^{20}{ }_{\text {» ainsi que des }}$ différents dialectes alémaniques et tessinois, choisissez une langue puis cliquez sur l'un des emplacements indiqués sur la carte. »

Em (a) Langues et (b) Dialectes, temos uma articulação do sentido de um em relação ao outro. Ainda, temos:

(a) Langues reescrito por (a') allemand, (a'’) Français, (a',') italien, (a',',) retoromance.

e

(b) dialectes reescrito por (b') Accent suisse

Temos em (a), (a'), (a'"'), (a',') uma operação de expansão e desenvolvimento com a reescrituração da língua pela frase escrita.
Alemão - "Wir wollen unter den kirschenbaum etwas ausruhen"
Francês - "On veut se reposer un peu sous ce cerisier"
Italiano - "Voliamo riposarci un attimo sotto questo ciliegio"
Reto-romance - "Nus lein serevegnir in tec quei tschascher"

Desse modo, podemos dizer que o sentido de Langues é redividido por um memorável de tradução e da identidade da língua, pois cada "língua" representa uma identidade linguística.

Temos, então, que:

$$
\begin{aligned}
& \text { (a2') Alemão é uma língua } \\
& \text { (a2'’) Francês é uma língua } \\
& \text { (a2',',) Italiano é uma língua } \\
& (\mathrm{a} 2 \text { ',',) Reto-romance é uma língua }
\end{aligned}
$$

Passemos então aos sentidos de (b) Dialectes.

Temos que (b) é reescriturado por (b') "accent suisse" e (b") "differents dialectes" em

"Pour avoir un écho du fameux «(b') accent suisse» ainsi que des "( $b$ ") différents dialectes alémaniques et tessinois", choisissez une langue puis cliquez sur l'un des emplacements indiqués sur la carte.

\footnotetext{
${ }^{20}$ Traduzimos accent por sotaque aqui.
} 
Desse modo, as relações de sentido entre (b') e (b') se dão em (b') numa substituição por especificação e em (b'), numa repetição por enumeração (que se repete em dialectes e tem seu sentido enumerado em allémaniques et tessinois).

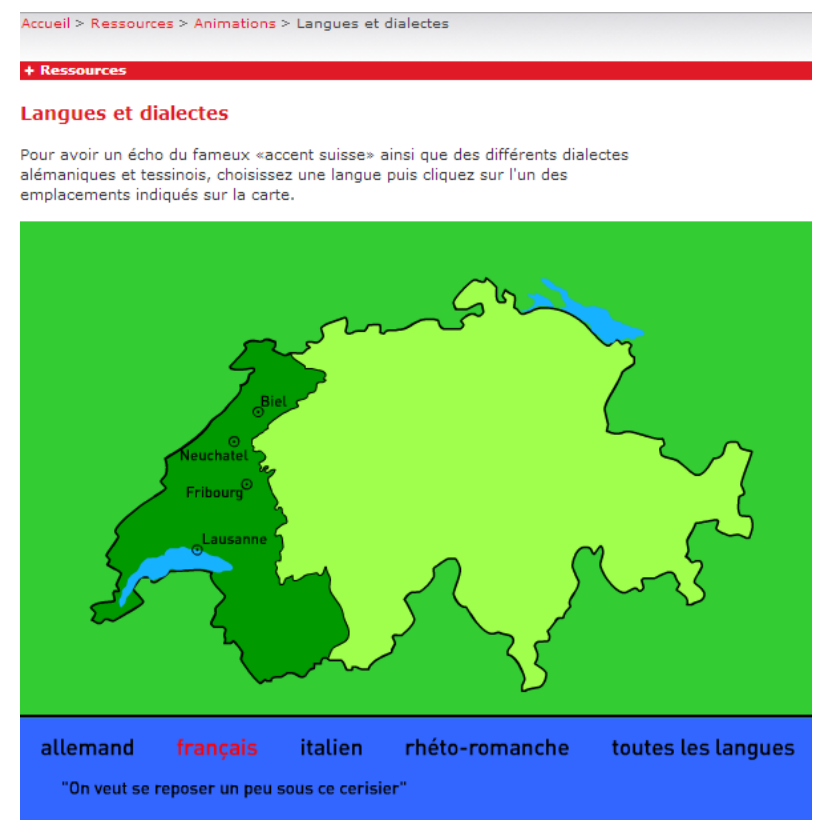

Figura 5 - Sotaques do francês, falados em cidades da Suíça.

Nesse mapa as operações dos locutores se dão nos modos de redividir os sentidos de (a) Langues et (b) Dialectes por substituição e especificação, em que "Langues" é reescrita por (I) allemand, (II) français, (III) italien e (IV) reto-romance e Dialectes pelo nome de cada cidade que reescreve o sentido de (b') Accent suisse por (b") Lausanne, (b"') Fribourg, (b",') Neuchâtel e (b",',) Biel, tal operação se dá no modo de redividir o sentido de cada língua e cada sotaque. Podemos interpretar, assim, que (b) é um hipônimo de (a), como indica no mapa da Figura 5.

Há outra relação que se dá em cada redivisão de b' que é posta pela representação do sotaque em seu registro. Temos de (b) à (b2",') uma substituição por especificação de lugar, como se pode ver em:

(b2') Em Lausanne se fala um "sotaque" (b2") Em Fribourg se fala um "sotaque" (b2",) Em Neuchâtel se fala um "sotaque" (b2",") Em Biel se fala um "sotaque". 
Trata-se, portanto, da substituição do nome da cidade (o regional, o geográfico) ao seu sotaque (variante oral).

Há ainda outra operação que se dá pela passagem (pelo clique em) de (b2'), (b2"'), (b2"') e (b2"',) à

(b3') On veut se reposer um peu sous ce cerisier.

(b3') On va un peut se reposer sous ce cerisier !?

(b3"') On veut se reposer un peu sous cerisier.

(b3',') On veut se reposer un peu sous ce cerisier.

Em cada um deles há uma expansão por desenvolvimento entre o sentido de (b2') à (b3'); de (b2'’) à (b3'”); de (b2',') à (b3'”'); (b2',',) à (b3',',) .

Trata-se de uma operação constituída pelo geográfico (memorável) e da variação (oralidade). E, assim, podemos interpretar que:

(b4') O sotaque varia em função do lugar.

Há, ainda, outra relação entre aquilo que (II) français significa e os enunciados dos nomes das cidades em (b2'), (b2’'), (b2',') e (b2','’). Dito de outro modo, há aí uma operação de substituição por especificação entre o hiperônimo (II) e seus hipônimos (b2'), (b2'’), (b2'’') e (b2','’).

É importante ressaltar que cada procedimento é operado pelo locutorWebEstado, e este é constituído pelo modo como é recortado especificamente pelo memorável da variação e da geografia da língua, pelo saber sobre a língua. Assim, os sentidos das designações Langues et Dialectes se constiuem numa relação transversal com os seus reescriturados. A relação não é segmental, pois não se dá na frase, nem em orações, se dá no modo como a enunciação organiza a textualidade do mapa das línguas, na animação.

Já na relação entre língua e dialeto, na animação, dialeto reescreve por substituição e especificação o seu hiperônimo, pois em cada registro oral do dialeto referido pelo nome da cidade, pelo modo de designar, recortado pela geografia, já que a relação é regional, tem-se um registro específico. Nesse sentido, o sentido de língua determina o sentido do dialeto, como podemos representar no seguinte domínio Semântico de Determinação ${ }^{21}$, o DSD. Juntamente, no mesmo gráfico, apresentamos o

\footnotetext{
${ }^{21}$ Levando-se em conta a relação entre os enunciados e as reescriturações, conforme Guimarães (2007), poderíamos representar a determinação do sentido a palavra no seguinte gráfico de um Domínio Semântico de Determinação Os símbolos $\uparrow, \perp, \dashv$ e $\vdash$, em qualquer direção, significam "determina"; o traço - significa sinonímia; um traço maior em negrito, que divide o DSD, significa antonímia. Todo DSD é demarcado por linhas que o circundam.
} 
exemplo da Língua, representada no texto escrito pelas frases, que em português significam "Queremos repousar um pouco embaixo dessa cerejeira".

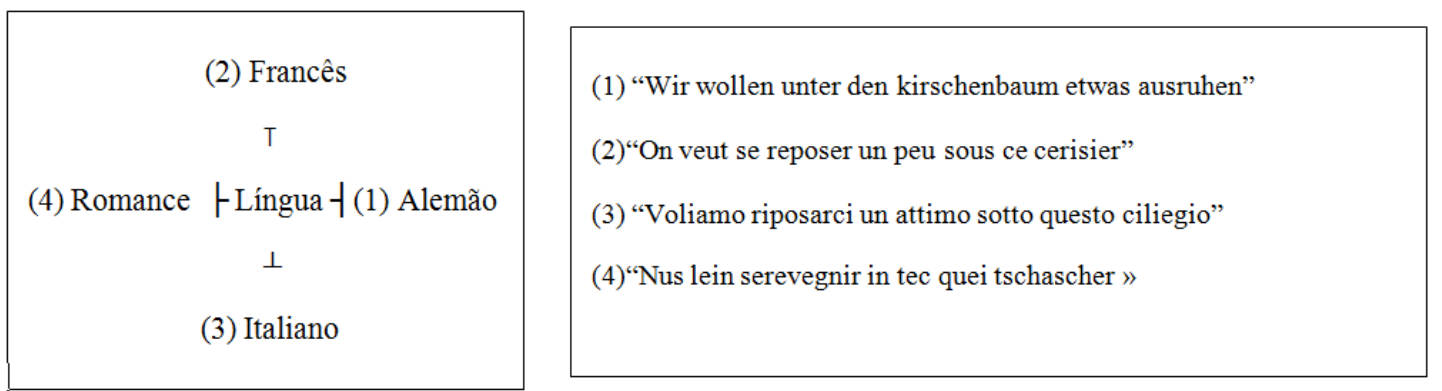

Gráfico 1 - DSD do sentido de Língua

A língua é que redistribui o dialeto e o acento, e nessa redistribuição cruzam-se o oficial, o geográfico e o nacional no modo de reparti-los, visto que o "modelo" do uso redivide o modo como se diz no dialeto ou sotaque (caso da diferença no francês). Textualmente, temos então: Língua, no exemplo escrito, dialeto e sotaque, no exemplo falado (registro). Há uma mudança na textualidade do site, do escrito ao oral, à medida que os locutores operam os sentidos de Langues et dialectes, postos pelas operações enunciativas do locutor-WebEstado, em seu modo de escrever, pela passagem de (b2'), (b2"'), (b2"') e (b2"',') à (b3'), (b3'”), (b3',') e (b3"',').

\section{Considerações}

A partir dessas análises sobre os modos de dividir e distribuir Línguas e Dialetos no site em questão, pudemos ler os textos de dois modos, ao menos. O primeiro é o que diz respeito à instrução de leitura nas oito línguas para as quais o site pode ser traduzido. As três traduções, em alemão, francês e italiano apresentam diferentes versões caracterizadas pela instrução significada em cada língua. Outro ponto é o modo como essa identidade se representa, pela "repartição" das línguas na Suíça, em suas línguas nacionais e oficiais, as três acima mais o reto-romance. No segundo modo, as diferentes enunciações em torno das Línguas e dos Dialetos se caracterizam pelas operações do locutor-WebEstado.

A enunciação de um link se caracteriza, portanto, pelo acesso, pela instrução. Instituem uma ruptura, demarcam um lugar e um modo de acesso à leitura. Enunciativamente, então, o link significa uma regulação no tempo de leitura, que organiza textualmente os sentidos do que se pode ler anteriormente ou posteriormente, 
como, por exemplo, dos links do nome até a introdução do texto e depois nas designações das línguas e dos dialetos, que estão representados em um mapa, cuja repartição geográfica configura a especificidade da Língua, enquanto modalidade de escrita, pelo exemplo dado na língua normatizada em alemão, francês, italiano e retoromance e, ainda, a temporalidade dos acontecimentos de enunciação, organizando cada texto, pelo modo de recortar o memorável, significa a identidade das línguas, como pode ser visto no texto em suas diferentes versões, em alemão, em francês, em italiano.

No agenciamento enunciativo (cf. GUIMARÃES, 2002), o agenciamento político da enunciação, que toma os falantes e determina as cenas enunciativas, que determina o lugar de dizer do locutor, observa-se como é possível rememorar uma política de tradução, na qual se retoma o lugar de fala da Política linguística, para atingir a distribuição mais democrática possível. No segundo modo de recortar mostra-se, em alguns pontos específicos, a descrição dos sentidos da designação de línguas: o locutor (e o leitor/Alocutário) e seu modo de representar as Línguas e os Dialetos, na textualidade do site. Ressalta-se, então, que as relações entre os sentidos das designações são construídas no modo como o locutor-WebEstado significa as línguas: o alemão, o francês, o italiano e o reto-romance, como língua e sua representação na frase escrita, e os seus dialetos, as variantes, reescriturados por substituição e especificação significados na designação do nome das cidades/regiões, onde elas são faladas. Nesse sentido, a questão da representação, da escrita e a produção do sentido da designação das línguas instituem a língua que se fala em cada uma daquelas regiões, configurando a dimensão espacial, geográfica e empírica das relações entre as línguas ali faladas. Pode-se concluir disso, ainda, que esse cruzamento de designações entre língua e sua variante, seu dialeto, seu sotaque e seu acento constrói-se no modo de enunciar o texto. Ou seja, há um aspecto descritivo e empírico no modo de textualizar, que significa o que é e o que não é uma língua por critérios de ordem geográfica. Desse modo, o francês, o alemão, o italiano, o romance não são as línguas faladas nessa região. Elas são as línguas que constroem as relações identitárias dos falantes, dos falantes das línguas significadas pelos nomes das cidades, dos cantões, das regiões linguísticas. Tal modo de escrever e reescrever essas enunciações mostra que o funcionamento da designação de língua no texto rememora o que é uma língua e suas variantes, em seu modo de representar, (re)formulando seus sentidos, em cada enunciação da palavra francês, alemão, italiano, línguas, dialetos, sotaques e acentos. 
Nesse sentido, a questão das línguas da e na Suíça representadas no site, retomam o modo como a Confederação Helvética reescreve a repartição das línguas aos falantes, diferentemente de outros países da Europa, como a França e a Alemanha, que tiveram a língua como principal elemento político de constituição do Estado-nação, como demonstrado na análise sobre os domínios dos endereços que dão acesso aos sites que têm como principal ponto a abreviação do nome da língua (.$d e ; . f r ; . i t)$. O site de relações internacionais da Suíça, portanto, tem a ver com o modo como a Suíça textualiza a História e representa seus falantes e suas línguas.

\section{REFERÊNCIAS}

COSTA, Carlos Irineu. Glossário. In : LÉVY, P. Cibercultura. Trad. Carlos Irineu da Costa. São Paulo: Editora 34, 2010.

DEMANGEON, A. La géographie des langues - article ; n²15; vol.38, pg 427-438. In : Annales de Géographie. 1929.

DIAS, C. P. A discursividade da rede (de sentidos): a sala de bate-papo hiv. 2004. Tese de Doutorado - Universidade Estadual de Campinas (UNICAMP). Instituto de Estudos da Linguagem.

FERRARI, Pollyana. Hipertexto e Hipermídia: as novas ferramentas da comunicação digital (org). São Paulo: Contexto. 2013

GADET, F., PÊCHEUX, M. Há uma via para a Lingüística fora do logicismo e do sociologismo?. In: Escritos (3): 05-16. Campinas: LABEURB - UNICAMP, 1998.

GALLO, S. L. A internet como Acontecimento. In: INDURSKY, F; MITTMANN, S; LEANDRO FERREIRA, MC. (Org.). Memória e História da Análise do Discurso. Campinas,SP: Mercado de Letras, 2011, v. , p. 255-270.

GUIMARÃES, E. Semântica do acontecimento: um estudo enunciativo da designação. Campinas, SP: Pontes Editores, 2002.

GUIMARÃES, Eduardo. Domínio Semântico de Determinação. in. A palavra: forma e sentido. GUIMARÃES, E; MOLLICA, M. C. Campinas, SP: Pontes/RG, (2007). P.7796. (2007)

GUIMARÃES, E. A Enumeração: Funcionamento Enunciativo e Sentido. Cadernos de Estudos Lingüísticos. (UNICAMP), v. 1, p. 49-68, 2009.

Editores 2011.

Análise de texto: Procedimentos, Análises, Ensino. Campinas: RG

GRIN, François. Gestion "à la Suisse" de la diversité linguistique : un succès menacé par l'économie, 1999.

LÉVY, Pierre. O que é o virtual? São Paulo: Ed. 34 (Coleção TRANS). 1996.

NAPPEY, G. \& Mix \& Remix. Histoire Suisse. 2013.

RANCIÈRE, J. [1994]. Os nomes da história: uma poética do saber. Campinas, SP: Pontes, 1994. 
RANCIÈRE, J. O desentendimento. Ed. 34. São Paulo. 1996.

RODRÍGUEZ-ALCALÁ, C. Políticas Públicas de Direito à Língua e Consenso Etnocultural: Uma Reflexão Crítica. In. Discurso e Políticas Públicas: A Fabricação do Consenso. ORLANDI, E. (org.): Campinas, Ed. RG, 2010.

SWITZERLAND. Département fédéral des affaires étrangères. Présence Suisse. Último acesso 22/06/2014. Disponível em <www.swissworld.org/fr/>.

STAHLHAUER, André S. M. A representação de línguas no ciberespaço: um funcionamento enunciativo na contemporaneidade. Tese de Doutorado. Outubro/2014. UFSCar-São Carlos-SP. Impresso.

André S. M. Relação de línguas no espaço enunciativo da propaganda: a argumentação, a enunciação e o político. Dissertação de Mestrado. Fev/ 2010. UFSCar-São Carlos-SP. Impresso.

Data de Recebimento: 16/03/2016

Data de Aprovação: 20/06/2016 


\section{Para citar essa obra:}

STAHLHAUER, A. S. M. SILVA, S. M. S. A geografia, a identidade das línguas e as divisões de langues e dialectes no site de relações estrangeiras da Suíça: reflexões sobre o sentido da designação no texto. In: RUA [online]. $n^{\circ}$. 22. Volume 2, p. 573 - 591 ISSN 1413-2109/2179-9911 - Junho/2016. Consultada no Portal Labeurb - Revista do Laboratório de Estudos Urbanos do Núcleo de Desenvolvimento da Criatividade. http://www.labeurb.unicamp.br/rua/

Capa: Figura 1 - Línguas e dialetos. Alemão suíço

\section{Laboratório de Estudos Urbanos - LABEURB}

Núcleo de Desenvolvimento da Criatividade - NUDECRI

Universidade Estadual de Campinas - UNICAMP

http://www.labeurb.unicamp.br/

\section{Endereço:}

LABEURB - LABORATÓRIO DE ESTUDOS URBANOS

UNICAMP/COCEN / NUDECRI

CAIXA POSTAL 6166

Campinas/SP - Brasil

CEP 13083-892

Fone/ Fax: (19) 3521-7900

Contato: http://www.labeurb.unicamp.br/contato 